\title{
Iron Acquisition from Fe-Pyoverdine by Arabidopsis thaliana
}

\author{
Gérard Vansuyt, ${ }^{1}$ Agnès Robin, ${ }^{1}$ Jean-François Briat, ${ }^{2}$ Catherine Curie, ${ }^{2}$ and Philippe Lemanceau ${ }^{1}$ \\ 'INRA-Université de Bourgogne, UMR 'Microbiologie et Géochimie des Sols', 17 rue Sully, BV 86510, 21034 Dijon cedex, \\ France; ' ${ }^{2}$ MR 5004 CNRS/Université Montpellier II/ ENSAM/INRA ‘Biochimie et Physiologie Moléculaire des Plantes', Place \\ Pierre Viala, 34060 Montpellier cedex I, France
}

Submitted 14 January 2006. Accepted 17 October 2006.

\begin{abstract}
Taking into account the strong iron competition in the rhizosphere and the high affinity of pyoverdines for $\mathrm{Fe}$ (III), these molecules are expected to interfere with the iron nutrition of plants, as they do with rhizospheric microbes. The impact of Fe-pyoverdine on iron content of Arabidopsis thaliana was compared with that of Fe-EDTA. Iron chelated to pyoverdine was incorporated in a more efficient way than when chelated to EDTA, leading to increased plant growth of the wild type. A transgenic line of $A$. thaliana overexpressing ferritin showed a higher iron content than the wild type when supplemented with Fe-EDTA but a lower iron content when supplemented with Fe-pyoverdine despite its increased reductase activity, suggesting that this activity was not involved in the iron uptake from pyoverdine. A mutant knockout iron transporter IRT1 showed lower iron and chlorophyll contents when supplemented with Fe-EDTA than the wild type but not when supplemented with Fe-pyoverdine, indicating that, in contrast to iron from EDTA, iron from pyoverdine was not incorporated through the IRT1 transporter. Altogether these data suggest that iron from $\mathrm{Fe}$ pyoverdine was not incorporated in planta through the strategy I, which is based on reductase activity and IRT1 transporter. This is supported by the presence of pyoverdine in planta as shown by enzyme-linked immunosorbent assay and by tracing ${ }^{15} \mathrm{~N}$ of ${ }^{15} \mathrm{~N}$-pyoverdine.
\end{abstract}

Additional keyword: Pseudomonas fluorescens.

Although it is the fourth most common element in the earth's crust, at $\mathrm{pH}$ values compatible with plant growth, $\mathrm{Fe}(\mathrm{III})$ is precipitated mostly as hydroxides. Iron is also associated with phosphorus and colloids and, therefore, the concentration of $\mathrm{Fe}(\mathrm{III})$ available for living organisms in cultivated soils is usually low (Lindsay 1979). In the rhizosphere, this concentration is even lower due to the uptake of this ion by both roots and microflora. The combined low concentration of $\mathrm{Fe}(\mathrm{III})$ in solution (offer) together with the requirements of aerobic organisms (plants and microorganisms) (demand) leads to an especially high level of competition for $\mathrm{Fe}(\mathrm{III})$ in the rhizosphere (Guerinot and Yi 1994; Loper and Buyer 1991). Most aerobic organisms have therefore developed active strategies for iron uptake.

In plants, two types of strategies have been described for the active uptake of iron by the roots (Curie and Briat 2003). Strategy I, found in dicotyledonous and nongraminaceaous mono-

Corresponding author: P. Lemanceau; Telephone: +33 3806930 56; Fax: +333806932 24; E-mail: lemanceau@dijon.inra.fr cotyledonous plants, involves i) the excretion of protons (Bienfait 1985; Guerinot and Yi 1994), ii) the reduction of $\mathrm{Fe}(\mathrm{III})$ to the more soluble $\mathrm{Fe}$ (II) form by an NADPH-ferric chelate reductase (Robinson et al. 1999; Yi and Guerinot 1996), and iii) plasmalemma transport of $\mathrm{Fe}(\mathrm{II})$ by transporters (Eide et al. 1996; Vert et al. 2002). Strategy II, found in grasses, involves i) the synthesis of phytosiderophores, which form a complex with Fe(III) (Von Wirén et al. 2000) and ii) the intake by roots of the $\mathrm{Fe}(\mathrm{III})$ phytosiderophore complex by a specific transporter (Curie et al. 2001; Von Wirén et al. 1994).

The active strategy of iron uptake by microorganisms is based on siderophores and on Fe-siderophore membrane receptors (Neilands 1981). As an example, under iron-deficient conditions, fluorescent pseudomonads synthesize siderophores, called pyoverdines, showing a high affinity for $\mathrm{Fe}(\mathrm{III})$ (Meyer and Abdallah 1978) and membrane receptors that are usually specific (Hohnadel and Meyer 1988). Pyoverdines are chromopeptides composed of a quinoleinic chromophore bound together with a peptide and an acyl chain (Meyer et al. 1987). Synthesis of pyoverdines and corresponding protein membrane receptors occurs only in response to cellular iron deficiency resulting from a low iron content in the environment (low offer) but is repressed in non-iron stress conditions (Meyer and Abdallah 1978). When the bacterial density is high and corresponds to a significant demand in iron, pyoverdine synthesis also is regulated by the phenomenon of quorum sensing through the production of acyl homoserines lactones (AHLs) (Stintzi et al. 1998). In the rhizosphere, there is both i) a strong competition for iron uptake between microbes and plant roots and ii) a high density of fluorescent pseudomonads leading to a significant frequency of populations producing AHLs (Elasri et al. 2001). Therefore, rhizosphere conditions appear to be favorable to pyoverdine synthesis. Indeed, this synthesis was shown to occur using antibodies raised against Fe-pyoverdine (Buyer et al. 1990) as well as an ice-nucleation reporter gene, inaZ, expressed under the control of an ironregulated promoter involved in pyoverdine synthesis (Duijff et al. 1999; Loper and Lindow 1994). The use of Pseudomonas fluorescens Pf-5 containing pvd-inaZ further enabled Loper and Henkels (1999) to show the low biological availability of iron in soil and rhizosphere.

This efficient pyoverdine-mediated iron uptake was shown to give a competitive advantage to model strains of fluorescent pseudomonads in the rhizosphere (Mirleau et al. 2000, 2001) and was involved in their antagonistic activity against pathogenic fungi (Duijff et al. 1999; Lemanceau et al. 1992, 1993). Indeed, efficient iron competitor strains of fluorescent pseudomonads have been proposed as potential biocontrol agents (Kloepper et al. 1980; Loper and Buyer 1991). 
Taking into account the strong iron competition in the rhizosphere and the high affinity of pyoverdines for iron, these molecules and the corresponding producing bacteria are expected to interfere with the iron nutrition of plants, as they do with rhizospheric microbes. The aim of this study was to assess the impact of purified pyoverdine, from the biocontrol P. fluorescens C7 (Lemanceau and Alabouvette 1991), chelated to iron on the iron nutrition of a strategy I plant species (Arabidopsis thaliana ecotype Columbia [Col]). In addition to wild-type plants, two modified genotypes affected in their iron uptake were used. The first is a mutant affected in IRT1, the major root $\mathrm{Fe}(\mathrm{II})$ transporter from $A$. thaliana $\mathrm{Col}$ (Henriques et al. 2002). The second, produced in the present study, is a transgenic A. thaliana Col plant overexpressing the iron storage protein ferritin. Such transgenic lines have already been described using tobacco (Van Wuytswinkel et al. 1999). They contain an increased amount of iron sequestrated within the overexpressed ferritin, resulting from an activation of the root ferric-chelate reductase, an important component of the root iron uptake system of nongraminaceous plants.

\section{RESULTS}

\section{Characterization}

of the ferritin overexpressing transgenic line.

In order to test the effect of iron storage deregulation, transgenic $A$. thaliana Col plants overexpressing soybean ferritin ectopically in the plastids were generated. Soybean ferritin protein abundance in shoots from kanamycin-resistant T3 transgenes (P1.8, P5.6, P21.6, and P28.8) was tested by Western blot analysis. Compared with untransformed plants, P1.8

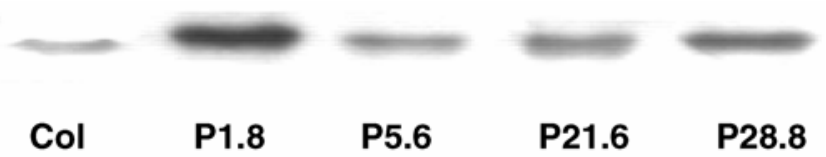

Fig. 1. Soybean ferritin expression and endogen biosynthesis of Arabidopsis thaliana Columbia wild type $(\mathrm{Col})$ and transgenic lines. Immunodetection of soybean ferritin subunit expressed in selected T3 transgenic lines (P1.8, P5.6, P21.6, and P28.8) by Western blot. plants showed the highest level of overaccumulation of ferritin (Fig. 1). The iron content in shoots of the four T3 transgenic lines, grown in vitro in the presence of $25 \mu \mathrm{M}$ Fe-EDTA, was analyzed. All transgenic lines accumulated significantly more iron than the control (Fig. 2). However, the P1.8 line accumulated slightly more iron than the other transgenic lines analyzed and presented the same macroscopic phenotype as the wild type. Therefore, the P1.8 line was chosen as ferritin overexpressor (OV ferritin) for further experiments.

\section{Effect of Fe-pyoverdine and Fe-EDTA on plant growth.}

We next compared the effect of providing iron as Fe-pyoverdine or Fe-EDTA on plant growth. Iron supplementation with $\mathrm{Fe}$-pyoverdine or Fe-EDTA promoted growth of the wild type and the OV ferritin line (Table 1); this promotion being significantly higher with Fe-pyoverdine than with Fe-EDTA in the wild type but not in the OV ferritin line. In contrast, none of the chelate promoted plant growth compared with the unsupplemented control in the KO IRT1 mutant.

Growth of the OV ferritin line was always significantly higher than the wild type, whereas that of the KO IRT1 mutant was always lower than the wild type, except in the unsupplemented control.

Table 1. Effect of Fe-pyoverdine and Fe-EDTA on plant growth of the wild-type ecotype Col (WT), the overexpressing (OV) ferritin transgenic line, and IRT1 KO mutant ${ }^{2}$

\begin{tabular}{llcc}
\hline & \multicolumn{3}{c}{ Biomass (mg fresh weight/plant) } \\
\cline { 2 - 4 } & $-\mathbf{F e}$ & Fe-EDTA & Fe-pyoverdine \\
\hline WT & $1.58^{\mathrm{b}}{ }_{\mathrm{c}}$ & $2.80^{\mathrm{b}}{ }_{\mathrm{b}}$ & $3.29^{\mathrm{b}}{ }_{\mathrm{a}}$ \\
OV ferritin & $2.57^{\mathrm{a}} \mathrm{b}^{\mathrm{b}}$ & $4.12^{\mathrm{a}}$ & $4.63^{\mathrm{a}}{ }^{\mathrm{a}}$ \\
IRT1 KO & $2.24^{\mathrm{a}}{ }_{\mathrm{a}}$ & $2.18^{\mathrm{c}}{ }_{\mathrm{a}}$ & $2.31^{\mathrm{c}_{\mathrm{a}}}$ \\
\hline
\end{tabular}

${ }^{\mathrm{z}}$ Plant growth was assessed in 14-day-old plants by measuring their biomass. Plants were grown for 7 days without any iron supplementation and for 7 more days after having been supplemented with $50 \mu \mathrm{M} \mathrm{Fe}$-pyoverdine or Fe-EDTA or not supplemented $(-\mathrm{Fe})$. Letters indicate values significantly different as measured by the Fisher's least significant difference test $(P \leq 0.05)$. Letters in subscript correspond to comparisons of differing iron statuses within a given plant genotype. Letters in superscript correspond to comparisons between the plant genotypes for a given iron status.

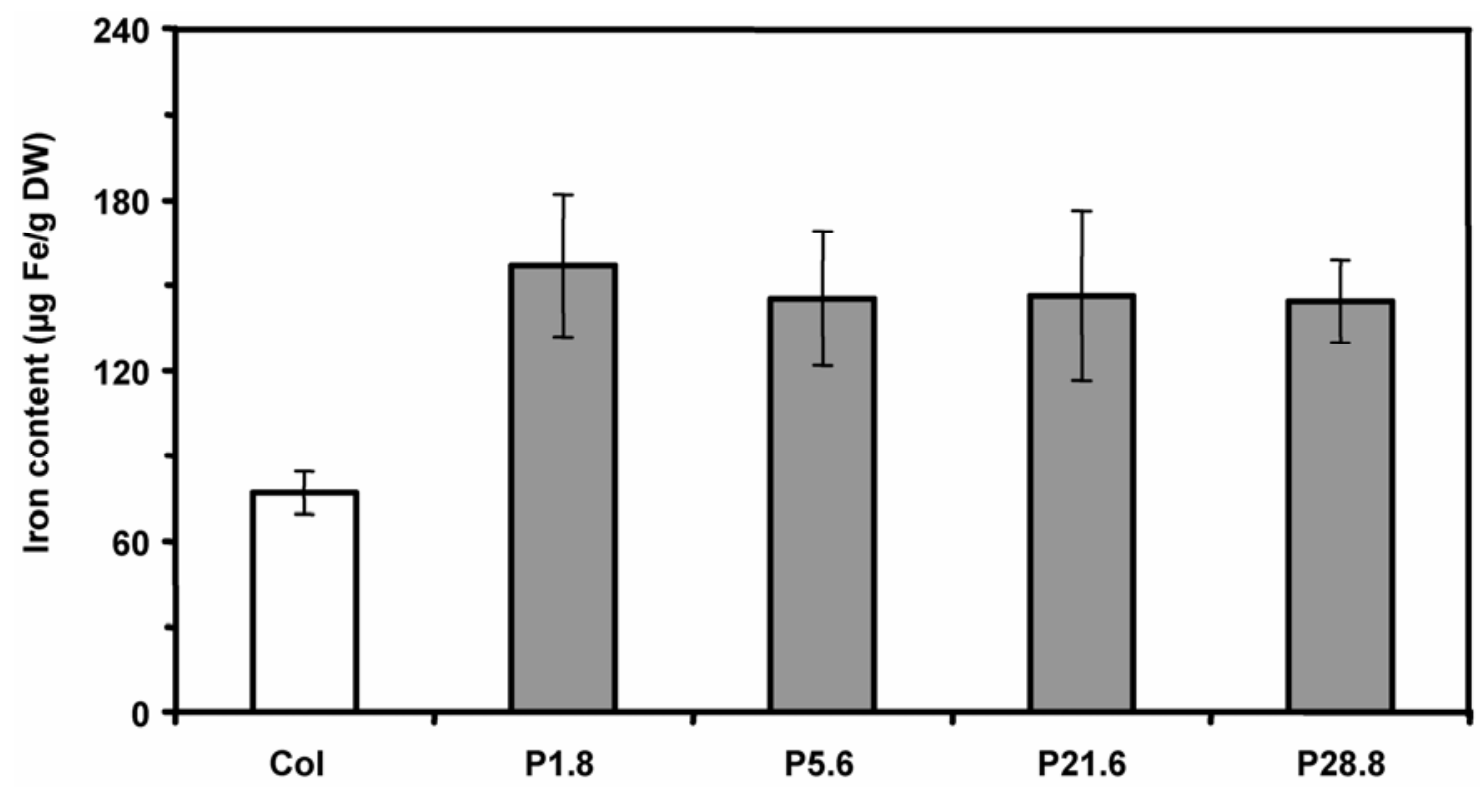

Fig. 2. Iron content in shoots of Arabidopsis thaliana Columbia wild type (Col) and transgenic lines (P1.8, P5.6, P21.6, and P28.8) overexpressing soybean ferritin. Means values and standard deviations were calculated from four independent experiments. 
Effect of Fe-pyoverdine and Fe-EDTA

on chlorophyll content and ferric reductase activity.

Fe-pyoverdine and Fe-EDTA significantly increased chlorophyll content of the wild type and of the OV ferritin line but not that of the IRT1 KO mutant (Table 2). Supplementation of Fe-pyoverdine stimulated ferric reductase activity both in the wild type and OV ferritin line; this stimulation being significantly higher in the OV ferritin line. Supplementation of FeEDTA promoted reductase activity in the wild type but depressed that activity in the OV ferritin line and KO IRT1 mutant. The promotion of reductase activity by Fe-pyoverdine was significantly higher than that by Fe-EDTA in the wild type and OV ferritin transgenic line but not in the KO IRT1 mutant.

Chlorophyll content and ferric reductase activity were always significantly higher in the OV ferritin line than in the wild type and IRT1 KO mutant. Chlorophyll content was lower in the IRT1 KO mutant than in the wild type when supplemented with Fe-EDTA but not when supplemented with Fe-pyoverdine, and reductase activity was less expressed when supplemented with either chelates.

\section{Effect of Fe-pyoverdine and Fe-EDTA on plant iron content.}

For all experimental conditions (various plant genotypes and varying iron status), the iron content was significantly higher in roots than in shoots (Table 3 ). For all plant genotypes, the iron content in roots and shoots was significantly higher when supplemented with Fe-pyoverdine than with Fe-EDTA and when supplemented with Fe-EDTA than when not supplemented (Table 3). When considering separately the roots and shoots, the highest iron content was also always recorded in the presence of Fe-pyoverdine, whereas FeEDTA did not increase significantly the shoot iron content of either the OV ferritin line or the IRT1 KO mutant as compared with the unsupplemented control.

The OV ferritin transgenic line accumulated more iron than the wild type in iron-stress conditions and when supplemented with Fe-EDTA but not when supplemented with Fe-pyoverdine. As expected, the IRT1 KO mutant accumulated signifi- cantly less iron than the wild type in iron-stress conditions and when supplemented with Fe-EDTA. In contrast, this accumulation was not significantly different when supplemented with $\mathrm{Fe}$-pyoverdine. In roots, iron content of the OV ferritin line was significantly the highest when supplemented with $\mathrm{Fe}$ EDTA but, significantly, the lowest when supplemented with Fe-pyoverdine. In shoots, the iron content of the three plant genotypes did not differ significantly when supplemented with Fe-EDTA but was significantly the highest in the IRT1 KO mutant when supplemented with Fe-pyoverdine.

\section{Quantification of pyoverdine in roots.}

Pyoverdine concentrations in soluble protein extracts from roots were assessed by enzyme-linked immunosorbent assay (ELISA) procedure after spraying the roots with Fe-pyoverdine (Table 4). Pyoverdine was detected in roots but not in shoots of all plant genotypes. Pyoverdine concentration was, significantly, the highest in the IRT1 KO mutant and the lowest in the wild type (Table 4).

The presence of pyoverdine in roots but also in shoots of all plant genotypes was confirmed by measurements of pyoverdine labeled with ${ }^{15} \mathrm{~N}$ (Table 4). The amount of ${ }^{15} \mathrm{~N}$ was signifi-

Table 4. Quantification of pyoverdine in roots of the wild-type ecotype Col (WT), overexpressing (OV) ferritin transgenic line, and IRT1 KO mutant ${ }^{\mathrm{Z}}$

\begin{tabular}{|c|c|c|c|c|}
\hline & \multicolumn{2}{|c|}{ Pyoverdine ng/mg } & \multicolumn{2}{|c|}{$\begin{array}{c}{ }^{15} \mathrm{~N} \text { pyoverdine } \\
\mu \mathrm{M}{ }^{15} \mathrm{~N} / \mathrm{g} \text { dry weight }\end{array}$} \\
\hline & Roots & Shoots & Roots & Shoots \\
\hline WT & $19.30 \mathrm{c}$ & n.d.* & $120.53 \mathrm{~b}$ & $18.88 \mathrm{~b}$ \\
\hline OV ferritin & $27.82 \mathrm{~b}$ & n.d. & $76.35 c$ & $13.30 \mathrm{c}$ \\
\hline IRT1 KO & $33.38 \mathrm{a}$ & n.d. & $162.36 \mathrm{a}$ & $28.64 \mathrm{a}$ \\
\hline
\end{tabular}

${ }^{\mathrm{z}}$ Pyoverdine quantification was assessed by enzyme-linked immunosorbent assay and by analysis of ${ }^{15} \mathrm{~N}$ (from ${ }^{15} \mathrm{~N}$ Fe-pyoverdine) on 14-daysold plants. Plants were grown for 7 days without any iron supplementation and for 7 more days after having been supplemented with $50 \mu \mathrm{M}$ Fe-pyoverdine or Fe-EDTA or not supplemented. Letters indicate values significantly different as measured by the Fisher's least significant difference test $(P \leq 0.10){ }^{*}=$ not detected

Table 2. Effect of Fe-pyoverdine and Fe-EDTA on chlorophyll content and ferric reductase activity of the wild-type ecotype Col (WT), the overexpressing (OV) ferritin transgenic line, and the IRT1 KO mutant ${ }^{2}$

\begin{tabular}{|c|c|c|c|c|c|c|}
\hline & \multicolumn{3}{|c|}{ Chlorophyll $\mu \mathrm{g} / \mathrm{mg}$ fresh weight $(\mathrm{FW})$} & \multicolumn{3}{|c|}{ Ferric reductase activity $\mu \mathrm{g} \mathrm{Fe}$ (III)ferrozine/h/mg FW } \\
\hline & $-\mathrm{Fe}$ & Fe-EDTA & Fe-pyoverdine & $-\mathrm{Fe}$ & Fe-EDTA & Fe-pyoverdine \\
\hline $\begin{array}{l}\text { WT } \\
\text { OV ferritin } \\
\text { IRT1 KO }\end{array}$ & $\begin{array}{l}0.18^{\mathrm{b}}{ }^{\mathrm{b}} \\
0.29^{\mathrm{a}} \\
0.17^{\mathrm{b}}{ }_{\mathrm{a}}\end{array}$ & $\begin{array}{l}0.29^{\mathrm{b}}{ }^{\mathrm{a}} \\
0.39^{\mathrm{a}} \\
0.18^{\mathrm{c}}{ }^{\mathrm{c}}\end{array}$ & $\begin{array}{l}0.31^{\mathrm{b}}{ }^{\mathrm{a}} \\
0.40^{\mathrm{a}} \\
0.21^{\mathrm{b}^{\mathrm{a}}}\end{array}$ & $\begin{array}{l}0.20^{\mathrm{c}} \mathrm{c} \\
0.54{ }^{\mathrm{a}} \\
0.32{ }^{\mathrm{b}}{ }_{\mathrm{a}}\end{array}$ & $\begin{array}{l}0.35^{\mathrm{b}} \mathrm{b} \\
0.45^{\mathrm{a}}{ }^{\mathrm{c}} \\
0.23{ }^{\mathrm{c}} \mathrm{b}\end{array}$ & $\begin{array}{l}0.51^{\mathrm{b}}{ }^{\mathrm{a}} \\
0.60^{\mathrm{a}} \\
0.26^{\mathrm{a}}{ }_{\mathrm{b}}^{\mathrm{c}}\end{array}$ \\
\hline
\end{tabular}

${ }^{2}$ Chlorophyll content and ferric reductase activity were measured in 14-day-old plants. Plants were grown for 7 days without any iron supplementation and for 7 more days after having been supplemented with $50 \mu \mathrm{M}$ Fe-pyoverdine or Fe-EDTA or not supplemented (-Fe). Letters indicate values significantly different as measured by the Fisher's least significant difference test $(P \leq 0.05)$. Letters in subscript correspond to comparisons of the differing iron statuses within a given plant genotype. Letters in superscript correspond to comparisons between the plant genotypes for a given iron status.

Table 3. Effect of Fe-pyoverdine and Fe-EDTA on iron content of the wild-type ecotype Col (WT), the overexpressing (OV) ferritin transgenic line, and IRT1 KO mutant ${ }^{2}$

\begin{tabular}{|c|c|c|c|c|c|c|c|c|c|}
\hline & \multicolumn{9}{|c|}{ Iron content $\mu \mathrm{g} \mathrm{Fe} / \mathrm{g}$ fresh weight } \\
\hline & \multicolumn{3}{|c|}{ Roots } & \multicolumn{3}{|c|}{ Shoots } & \multicolumn{3}{|c|}{ Total } \\
\hline & $-\mathrm{Fe}$ & Fe-EDTA & Fe-pyoverdine & $-\mathrm{Fe}$ & Fe-EDTA & Fe-pyoverdine & $-\mathrm{Fe}$ & Fe-EDTA & Fe-pyoverdine \\
\hline $\begin{array}{l}\text { WT } \\
\text { OV ferritin } \\
\text { IRT1 KO }\end{array}$ & $\begin{array}{r}107.96^{\mathrm{a}}{ }^{\mathrm{c}} \\
119.47^{\mathrm{a}} \\
66.66^{\mathrm{b}}{ }^{\mathrm{c}}{ }_{\mathrm{c}}\end{array}$ & $\begin{array}{l}135.18^{\mathrm{b}} \mathrm{b} \\
153.64^{\mathrm{a}}{ }^{\mathrm{b}} \\
104.96^{\mathrm{b}} \mathrm{b}\end{array}$ & $\begin{array}{l}204.62^{\mathrm{a}}{ }^{a} \\
177.788^{\mathrm{c}}{ }^{a} \\
187.13^{\mathrm{b}^{\mathrm{a}}}\end{array}$ & $\begin{array}{l}20.22^{\mathrm{b}}{ }^{\mathrm{b}} \\
28.06^{\mathrm{a}}{ }^{\mathrm{b}} \\
20.21^{\mathrm{b}}{ }_{\mathrm{b}}\end{array}$ & $\begin{array}{l}29.96^{\mathrm{a}} \mathrm{b} \\
31.79^{\mathrm{a}} \\
27.42^{\mathrm{a}} \mathrm{b}\end{array}$ & $\begin{array}{l}45.17^{\mathrm{b}}{ }^{\mathrm{a}} \\
41.43^{\mathrm{b}} \mathrm{a}^{\mathrm{a}} \\
70.69^{\mathrm{a}}{ }_{\mathrm{a}}\end{array}$ & $\begin{array}{r}128.18^{\mathrm{b}}{ }^{\mathrm{c}} \\
147.53 \mathrm{a}^{\mathrm{a}}{ }^{\mathrm{c}} \\
86.87^{\mathrm{c}}{ }_{\mathrm{c}}\end{array}$ & $\begin{array}{l}165.14{ }^{\mathrm{b}} \mathrm{b} \\
185.42 \mathrm{a}^{\mathrm{a}} \\
132.38 \mathrm{c}_{\mathrm{b}}^{\mathrm{c}}\end{array}$ & $\begin{array}{l}249.79^{\mathrm{a}}{ }^{\mathrm{a}} \\
219.24 \mathrm{~b}^{\mathrm{b}} \\
257.82^{\mathrm{a}}{ }^{\mathrm{a}}\end{array}$ \\
\hline
\end{tabular}

${ }^{2}$ Iron contents were measured in 14-day-old plants. Plants were grown for 7 days without any iron supplementation and for 7 more days after having been supplemented with $50 \mu \mathrm{M} \mathrm{Fe}$-pyoverdine or Fe-EDTA or not supplemented $(-\mathrm{Fe})$. Letters indicate values significantly different as measured by the Fisher's least significant difference test $(P \leq 0.10)$. Letters in subscript correspond to comparisons between the differing iron statuses within a given plant genotype. Letters in superscript correspond to comparisons between plant genotypes for a given iron status. 
cantly lower in shoots than in roots. In both roots and shoots, this amount was significantly higher in the IRT1 KO mutant than in the wild type and higher in the wild type than in the OV ferritin transgenic line.

\section{DISCUSSION}

The present study demonstrates the contribution of the pyoverdine produced by a biocontrol $P$. fluorescens to the iron nutrition of a plant species belonging to iron uptake strategy I. Fe chelated to pyoverdine was incorporated in a more efficient way than when chelated to EDTA, as indicated by the significant higher iron content of the plants fed with Fe-pyoverdine (Table 3). The higher iron accumulation of plants supplemented with Fe-pyoverdine than those supplemented with Fe-EDTA was recorded both in roots and shoots, even if the plant iron content was always significantly lower in shoots than in roots (Table 3). The lower iron content in shoots compared with roots is in agreement with our previous reports (Robin et al. 2006; Vansuyt et al. 2003) and with that of Masalha and associates (2000) indicating that iron was sequestered in the apoplasm in roots of sunflower. Our observations show that, in contrast with what was suggested by Becker and associates (1985), the iron-uptake strategy of an efficient iron competitor, such as the biocontrol $P$. fluorescens C7, does not hamper but even improves plant iron nutrition. These observations support and extend previous reports indicating an increase of iron content of other strategy I plants (peanut, cotton, cucumber) when supplemented with Fe-pyoverdine (Bar-Ness et al. 1991; Walter et al. 1994).

Despite iron supplementation with both chelates, plants remained chlorotic due to severe iron starvation (absence of any iron supplementation) prior to this supplementation, which was either not sufficiently high or was made too early before plant yielding to allow the increased iron content (Table 3) to promote chlorophyll synthesis and plant growth (Tables 1 and 2 ). In contrast, when cultivated in less iron-stressful conditions ( $5 \mu \mathrm{M}$ instead of $0 \mu \mathrm{M} \mathrm{Fe}$ ) before chelate addition, the plants were not chlorotic and the significantly higher iron content of those supplemented with $\mathrm{Fe}$-pyoverdine than those with $\mathrm{Fe}$ EDTA resulted in an increase of their chlorophyll content and biomass (data not shown).

The contribution of Fe-pyoverdine to iron plant nutrition was further analyzed thanks to the use of A. thaliana lines affected in either their ferritin level of expression or their major iron transporter (IRT1).

An overexpressor transgenic line of A. thaliana Col was obtained and, as previously described in tobacco (Vansuyt et al. 2003; Van Wuytswinkel et al. 1999), was shown to have an increased iron content compared with the wild type when supplemented with Fe-EDTA (Table 3), resulting from i) an expected higher storage capacity of iron from a greater ferritin production (Fig. 1) and from ii) an increased ferric-chelate reductase activity at the root level (Table 2). The increased iron content of the OV ferritin line in the presence of Fe-EDTA led to an increased biomass and chlorophyll content (Tables 1 and 2). Although the ferric reductase activity was also higher in the OV ferritin transgenic line than in the wild type when supplemented with Fe-pyoverdine, this higher activity was not related to an increased but, rather, to a decreased iron content, suggesting that ferric reductases did not contribute to the uptake of iron from Fe-pyoverdine (Table 3). Despite the lower iron content of the OV ferritin line than the wild type when supplemented with Fepyoverdine, its chlorophyll content and biomass remained higher than that of the wild type (Tables 1 and 2), probably due to its ferritin overexpression, which is known to increase the iron bioavailability in chloroplasts (Briat et al. 1999).
Beside the proton excretion (Bienfait 1985; Guerinot and Yi 1994) and the reduction of $\mathrm{Fe}(\mathrm{III})$ by reductases to the more soluble Fe(II) form (Robinson et al. 1999; Yi and Guerinot 1996), the iron-uptake Strategy I, to which belongs $A$. thaliana, is known to involve the plasmalemma transport of $\mathrm{Fe}(\mathrm{II})$ by iron transporters, IRT1 being the major of them (Curie et al. 2000; Eide et al. 1996; Vert et al. 2002). A knockout mutant of the IRT1 transporter, known to be essential for ferrous iron uptake in A. thaliana Col (Henriques et al. 2002), was also used. As reported by these authors, the iron content of the IRT1 KO mutant was significantly lower than the wild type when supplemented with Fe-EDTA (Table 3), this lower iron content leading to a reduction of the chlorophyll content (Table 2). In contrast, when supplemented with Fe-pyoverdine, the iron content of the IRT1 KO mutant did not significantly differ from that of the wild type; the shoot iron content of the mutant being even significantly higher than that of wild type (Table 3). However, this higher iron content in shoots did not induce an increased chlorophyll content (Table 2), suggesting that iron incorporated by the plant from Fe-pyoverdine had a low availability and that iron homeostasis in planta was modified. These results showing i) the similar iron contents of the IRT1 KO mutant and of the wild type when supplemented with Fe-pyoverdine, and ii) the lower iron content of that mutant than the wild type when supplemented with Fe-EDTA suggest that iron chelated to pyoverdine, in contrast to iron chelated to EDTA, was incorporated through a different transporter than IRT1. A possible alternative pathway for iron incorporation from Fe-siderophore was first proposed by Bienfait (1989), and we provide here, for the first time, experimental evidence to support this hypothesis.

The lower iron content of the OV ferritin transgenic line than the wild type together with the similar iron content of the KO IRT1 mutant and the wild type suggest that the incorporation of iron chelated to pyoverdine is related neither to the reductase activity nor to the IRT1 transporter. Therefore, the main components of the strategy I do not seem to be involved in the uptake of iron chelated to pyoverdine, suggesting that this iron would be incorporated through a different strategy.

To assess this hypothesis, the possible incorporation of the bacterial siderophore by the plant was evaluated by analogy to the iron-uptake strategy II based on phytosiderophores (Von Wirén et al. 2000) and their incorporation in roots when chelated with iron (Curie et al. 2001). For that purpose, two strategies were followed: one based on the use of a specific antibody raised against pyoverdine from $P$. fluorescens $\mathrm{C} 7$ and the other on the use of pyoverdine labeled with ${ }^{15} \mathrm{~N}$ amino acids. Antibodies raised against pyoverdines from other fluorescent pseudomonads were used in previous studies (Buyer et al. 1990). In contrast, production and use of ${ }^{15} \mathrm{~N}$-labeled pyoverdine has so far not been described. The immunological approach allowed the detection and quantification of pyoverdine in roots supplemented with Fe-pyoverdine (Table 4). To our knowledge, this is the first demonstration of the incorporation of pyoverdine by the plant. ${ }^{15} \mathrm{~N}$ of ${ }^{15} \mathrm{~N}$-pyoverdine was detected and quantified in roots but also in shoots. However, the concentration of ${ }^{15} \mathrm{~N}$ in shoots was sharply lower than in roots, and pyoverdine content may have then been below the detection limit of ELISA in that compartment. At this step, degradation of the peptidic chain of the corresponding siderophore in shoots cannot be excluded and we cannot rule out the possibility that ${ }^{15} \mathrm{~N}$ measured in shoots was no longer included in the pyoverdine molecule.

The pyoverdine content assessed by ELISA was higher in the IRT1 KO mutant than in the wild type, possibly resulting from the greater iron deficiency of the mutant (Table 3 ) that may have induced an increased incorporation of Fe-pyoverdine to compensate the lack of IRT1 transporter synthesis. The 
highest pyoverdine concentration in roots of the KO IRT1 mutant, as assessed by ELISA, is in agreement with the highest concentration of ${ }^{15} \mathrm{~N}$ of ${ }^{15} \mathrm{~N}$-pyoverdine in roots but also in shoots. The lowest value of ${ }^{15} \mathrm{~N}$ of ${ }^{15} \mathrm{~N}$-pyoverdine was measured in the OV ferritin roots and shoots; this observation is consistent with its lower iron content compared with that of the wild type and of the KO IRT1 mutant (Table 3). However, pyoverdine appeared to be more abundant in the OV ferritin line than in the mutant when assessed by ELISA. Variations in the expression of the quantitative values (nanograms of protein per milligram for ELISA and micromole per gram of dry weight of roots for ${ }^{15} \mathrm{~N}$ tracing) may account for this discrepancy, since root growth was taken into account with ${ }^{15} \mathrm{~N}$ tracing but not with ELISA.

Data reported here were obtained with A. thaliana Col, either wild type, mutated in IRT1, or overexpressing ferritin. Using the Wassilevskaija ecotype (Ws), similar results were recorded on the chlorophyll and iron contents and on the pyoverdine quantification in planta when comparing the wild type to its KO IRT1 mutant constructed by Vert and associates (2002) (data not shown). The consistence of the observations made with two different ecotypes strengthens the existence of a strategy I-independent mechanism for iron uptake from pyoverdine by A. thaliana.

In conclusion, our data show that iron from Fe-pyoverdine was incorporated by $A$. thaliana Col. This incorporation did not rely either on reductase activity or on the major IRT1 transporter, suggesting that the strategy I does not mediate this incorporation. These observations are consistent with the pyoverdine presence in planta, which suggests the acquisition of iron chelated to pyoverdine by $A$. thaliana roots by an as-yetundescribed pathway. Research studies are underway to identify this pathway and to localize pyoverdine in planta.

\section{MATERIALS AND METHODS}

\section{Plant growth conditions.}

The plant material was A. thaliana ecotypes $\mathrm{Col}$ or Ws and two modified genotypes, a transgenic line overexpressing the iron storage protein ferritin in the plastids (OV ferritin line) obtained in the present study and a knockout mutant in the iron transporter IRT1 (Henriques et al. 2002). The nutrient solution was a Hoagland solution containing $5 \mathrm{mM} \mathrm{KNO}_{3}$ and $\mathrm{Ca}\left(\mathrm{NO}_{3}\right)_{2}$, $2 \mathrm{mM} \mathrm{MgSO}_{4}, 50 \mu \mathrm{M} \mathrm{H}_{3} \mathrm{BO}_{3}, 5 \mu \mathrm{M} \mathrm{MnSO}_{4}, 15 \mu \mathrm{M} \mathrm{ZnSO}_{4} \cdot 7$ $\mathrm{H}_{2} \mathrm{O}, 3 \mu \mathrm{M} \mathrm{Na}_{2} \mathrm{MoO}_{4} \cdot 2 \mathrm{H}_{2} \mathrm{O}, 2.5 \mu \mathrm{M} \mathrm{KI}, 50 \mathrm{nM} \mathrm{CoCl}{ }_{2} \cdot 7$ $\mathrm{H}_{2} \mathrm{O}$, and $\mathrm{CuSO}_{4} \cdot 5 \mathrm{H}_{2} \mathrm{O}$. The solution $\mathrm{pH}$ was 6.3 .

Seeds were sterilized in $\mathrm{NaClO}(1.2 \%, \mathrm{vol} / \mathrm{vol}) / \mathrm{ethanol}$ ( $50 \% \mathrm{vol} / \mathrm{vol})$ for $25 \mathrm{~min}$, were washed three times with sterile ethanol/eau (96\%, vol/vol), and were dried in a flow chamber. Sterilized seeds were sown under sterile conditions (30 seeds per vertical 12 by $12-\mathrm{cm}$ square petri dish on a gel made with the nutrient solution, 10 g/liter of agar) (Sigma A 1296, Sigma, St. Louis). Plates were placed for $48 \mathrm{~h}$ at $4^{\circ} \mathrm{C}$ and then for 14 days in a culture chamber with a cycle of $16 \mathrm{~h}$ of light and $8 \mathrm{~h}$ of dark, light intensity of $300 \mu \mathrm{mol} / \mathrm{m} / \mathrm{s}$, and temperature of $21^{\circ} \mathrm{C}$. After 7 days, $1 \mathrm{ml}$ of either water, FeEDTA $(50 \mu \mathrm{M})$, or Fe-pyoverdine $(50 \mu \mathrm{M})$ was spread onto the nutrient gel including plant roots.

\section{Plasmid constructs and plant transformation.}

A purified soybean ferritin cDNA (Lescure et al. 1991) was used as a template to synthesize a DNA fragment (Fic-WT) by polymerase chain reaction, according to a procedure previously described (Van Wuytswinkel et al. 1995). It codes for the wild-type soybean ferritin precursor containing the transit peptide responsible for plastid targeting (Lescure et al. 1991). Primers used to amplify the Fic-WT cassette were 5'-CCCAG
TCTAGAGCCGCCACAAATCTTAG-3' and 5'-CCCAGGAG CTCGCAGCATCTTCCTAATCAAG-3' (Van Wuytswinkel et al. 1999). Engineering $X b a I$ and $S a c I$ restriction sites at the Fic-WT DNA fragment extremities enabled its directional cloning into the pBI121 binary vector (Clontech, Mountain View, CA, U.S.A.), in place of the XbaI-SacI GUS cassette, thereby placing their expression under the control of the Cauliflower mosaic virus $35 \mathrm{~S}$ promoter. The resulting plasmids then were introduced into Agrobacterium tumefaciens (strain LBA4404) by triparental mapping. A. thaliana Col primary transgenic lines (T1) were produced by using the floral dip protocol (Clough and Bent 1998). Progeny were selected for kanamycin resistance on in vitro Murashige Skoog media during plant growth and for ferritin expression in shoots by Western blots. The work reported here was performed with the T3 progeny propagated either in vitro to evaluate kanamycin resistance or in S2 greenhouse on Humin-substrate (Neuhaus N2, Klasmann-Deilmann, Geeste, Germany) for growth.

\section{Generation of transgenic $A$. thaliana Col plants overexpressing soybean ferritin.}

To test the effect of iron storage deregulation, transgenic $A$. thaliana Col plants (OV Ferritin) overexpressing soybean ferritin in the plastids (Fic-WT) were generated. A total of 31 FicWT independent transformed tobacco plants were obtained. Soybean ferritin expression in shoot samples from primary transgenic lines was tested by Western analysis after separation of $20 \mu \mathrm{g}$ of total protein extract (Bradford 1976) on a denaturing sodium dodecyl sulfate-polyacrylamide gel. Protein extracts were prepared from shoots of 14-day-old plants. Protein transfer to nitrocellulose filters was performed using a mini trans-blot cell (Biorad, Ivry-sur-Seine, France) according to the manufacturer's recommendations. Immunodetection was carried out using an antiserum raised against purified soybean ferritin, provided by E. C. Theil (CHORI, Oakland, CA). The second antibody was sheep anti-rabbit immunoglobulins coupled to peroxidase (Sigma). Peroxidase activity was detected by ECL (Amersham Bioscience, Orsay, France). Four independent transgenic lines (P1, P5, P21, and P28) were selected based on the number of integrated loci they contained (one or two) and on the various amounts of soybean ferritin expressed in their T2 generation. Transformation of P1, P5, P21, and P28 plants with pBI121 was controlled by checking their growth on a gel made with the nutrient solution ( $7 \mathrm{~g}$ per liter of agar) (Sigma A 1296) supplemented with kanamycin $(50 \mu \mathrm{M})$. Four T3 independent transgenic lines, P1.8, P5.6, P21.6, and P28.3, were analyzed by Western blot for their ferritin content.

Shoot iron contents of the transgenic lines (P1.8, P5.6, P21.6, and P28.8) were compared with that of the wild type on 14-day-old plants grown in the presence of $25 \mu \mathrm{M}$ Fe-EDTA.

\section{Measurement of chlorophyll content in shoots and ferric reductase activity in roots.}

Chlorophyll extraction and quantification by spectrophotometric method were performed according to Moran (1982), using three optical wavelengths $(644,647$, and $603 \mathrm{~nm})$. Approximately $20 \mathrm{mg}$ of fresh shoots was added to $1 \mathrm{ml}$ of dimethylformamide and the culture was stored at $-20^{\circ} \mathrm{C}$ for 48 h. The measurement was directly performed with the colored solution.

The ferric reductase activity was measured on the whole root systems by spectrophotometry of the purple-colored $\mathrm{Fe}(\mathrm{II})$-ferrozine complex (Yi and Guerinot 1996). Six plants for each of the four replicates were sampled, and their roots were immerged in a 2-ml solution containing $0.1 \mathrm{mM} \mathrm{Fe}$ (III)EDTA and $0.3 \mathrm{mM}$ Ferrozine (Sigma), and were shacked with a constant speed of $70 \mathrm{rpm}$ at a low light intensity and ambient 
temperature. After 30 min, the solution was sampled twice and the samples were analyzed by spectrophotometry at $562 \mathrm{~nm}$, using a molecular extinction coefficient of $28.6 \mathrm{mM} / \mathrm{cm}$.

\section{Determination of iron content in roots and shoots.}

Fresh tissues (50 to $200 \mathrm{mg}$ ) were washed twice for $15 \mathrm{~min}$ in $10 \mathrm{ml}$ of wash buffer $(1 \mathrm{mM}$ morpholineethanesulfonic acid [MES]-TRIS, pH 5.8; 5 mM EDTA Na $; 1 \mathrm{mM} \mathrm{KCl;} 0.5 \mathrm{mM}$ $\mathrm{CaSO}_{4}$; and $5 \mathrm{mM}$ dithionite), once in double-distilled water, and finally were dried onto filter paper prior to being weighed. Iron concentrations were determined by spectrophotometry at $535 \mathrm{~nm}$, using bathophenantrolin as $\mathrm{Fe}(\mathrm{II})$ chelator, after reduction with thioglycollic acid of the acid hydrolyzed samples (Lobréaux and Briat 1991). Measurements were duplicated and performed on four samples, each consisting of 60 plantlets.

\section{Production and purification of pyoverdine and preparation of $\mathrm{Fe}$-pyoverdine.}

P. fluorescens C7 (Lemanceau and Alabouvette 1991) was grown in succinate medium (Meyer and Abdallah 1978). Cultures were grown at $25^{\circ} \mathrm{C}$ for $48 \mathrm{~h}$ with shaking at $180 \mathrm{rpm}$. After $48 \mathrm{~h}$ of incubation, bacterial cells were harvested by centrifugation at $6,000 \mathrm{rpm}$ for $10 \mathrm{~min}$. The supernatant was adjusted at $\mathrm{pH} 6.0$ and was filtered before ion exchange chromatography onto a column of Amberlite XAD-4 (Sigma) according to the method used by Carson and associates (2000). The pyoverdine was eluted with methanol $50 \%$. It was then concentrated and lyophilized prior to storage at $4{ }^{\circ} \mathrm{C}$ in the dark. Supply of $\left(\mathrm{NH}_{4}\right)_{2} \mathrm{SO}_{4}{ }^{15} \mathrm{~N}$ to $99 \%$ was used for production of pyoverdine labeled with the ${ }^{15} \mathrm{~N}$ isotope. Fe-pyoverdine was obtained by mixing purified pyoverdine with inorganic $\mathrm{FeCl}_{3}$ at a molar ratio $1: 1$. Fe-pyoverdine solution $(50 \mu \mathrm{M})$ was adjusted to $\mathrm{pH} 4.5$ in order to mimic rhizosphere conditions (Jaillard et al. 1996) and was buffered with MES (10 $\mathrm{mM}) 72 \mathrm{~h}$ before spraying petri dishes. Fe-pyoverdine solution was stored at $4{ }^{\circ} \mathrm{C}$ in the dark and was filter-sterilized. Filtersterilized Fe-EDTA (Sigma E-6760) solution was prepared in $10 \mu \mathrm{M}$ MES, $\mathrm{pH} 4.5$.

\section{ELISA procedure for detection of pyoverdine in roots.}

Primary antibodies obtained from Eurogentec SA (Seraing, Belgium) were raised in a rabbit immunized with purified pyoverdine of the strain P. fluorescens C7 coupled to the keyhole-limpet hemocyanin peptide. Six subcutaneous injections of the suspension were performed at 3 -week intervals. The final booster was given 9 days before bleeding the rabbit.

Roots were washed twice with the wash buffer and three times with sterile water. Proteins were then extracted with 0.1 $\mathrm{M}$ Tris- $\mathrm{HCl}, \mathrm{pH} 7.5 ; 2 \%$ sucrose; $0.1 \%$ Triton X100; $10 \mathrm{mM}$ EDTA $\mathrm{Na}_{2}$; and $0.1 \% \quad \beta$-mercaptoethanol. Protein extracts were estimated according to the procedure of Bradford (1976). The measurements were repeated twice on three different samples, each made of 60 plantlets. Root protein extracts were diluted in phosphate-buffered saline to obtain $100 \mathrm{ng}$ of proteins for $100 \mu$ l loaded in each well of a microtitration plate (NUNC Maxisorp, San Diego, CA, U.S.A.). These extracts were coated directly overnight at $4^{\circ} \mathrm{C}$. Saturation of the unoccupied binding sites was allowed to take place in $200 \mu \mathrm{l}$ per well with Tris-casein buffer $(10 \mathrm{mM}$ Tris, $0.5 \%$ casein, $0.9 \%$ $\mathrm{NaCl}, \mathrm{pH}$ 7.6). Antisera were diluted 10,000-fold in Triscasein buffer $(100 \mu \mathrm{l}$ per well) and were incubated for $2 \mathrm{~h}$ at $37^{\circ} \mathrm{C}$. After three washes for $15 \mathrm{~min}$ each, the alkaline phosphatase conjugated to goat and anti-rabbit immunoglobulin $\mathrm{G}$ (Sigma) was added (100 $\mu \mathrm{l}$ per well, diluted 30,000 fold in Tris-buffered saline [TBS]) and was incubated for $1 \mathrm{~h}$ at $37^{\circ} \mathrm{C}$. After three washes in TBS, absorbance at $405 \mathrm{~nm}$ was recorded $2 \mathrm{~h}$ after substrate addition $(1 \mathrm{mg} / \mathrm{ml} \mathrm{p}$-nitrophenylphosphate in $10 \%$ diethanolamine, $\mathrm{HCl}, \mathrm{pH} 9.8 ; 0.5 \mathrm{mM} \mathrm{MgCl}_{2}$ ) on a microplate reader (Thermomax; Molecular Devices, Menlo Park, CA, U.S.A.). The reference reaction was performed with a preimmune serum and a root protein extract from a control plant (untreated with Fe-pyoverdine). Pyoverdine quantification was determined with a calibration curve $(0.1 ; 0.25 ; 0.5$; $1.0 ; 5.0 ; 10 \mathrm{ng}$ of pyoverdine).

\section{Statistical analysis.}

Statistical analyses were performed using the analysis of variance procedure of STATVIEW (software version 6; SAS Institute Inc., Cary, NC, U.S.A.). Letters indicate values significantly different according to the Fisher's least significant difference test.

\section{AKNOWLEDGMENTS}

The authors are grateful to S. Lobréaux for his contribution to the generation of $\mathrm{OV}$ ferritin transgenic line, to $\mathrm{C}$. Koncz for providing seeds of the KO IRT1 mutant of A. thaliana Col, and to P. Tillard and C. Bréchet for the ${ }^{15} \mathrm{~N}$ analyses.

\section{LITERATURE CITED}

Bar-Ness, E., Chen, Y., Hadar, Y., Marschner, H., and Römheld, V. 1991. Siderophores of Pseudomonas putida as an iron source for dicot and monocot plants. Plant Soil 130:231-241.

Becker, J. O., Hedges, R. W., and Messens, E. 1985. Inhibitory effect of pseudobactin on the uptake of iron by higher plants. Appl. Environ. Microbiol. 49:1090-1093.

Bienfait, H. F. 1985. Regulated redox process at the plasmalemma of plant root cells and their function in iron uptake. J. Bioenerg. Biomembr. 17:73-83

Bienfait, H. F. 1989. Prevention of stress in iron metabolism of plants. Acta Bot. Neerl. 38:105-129.

Bradford, M. M. 1976. A rapid and sensitive method for the quantification of microgram quantities of protein utilizing the principal of protein dye binding. Anal. Biochem. 72:248-254.

Briat, J. F., Lobréaux, S., Grignon, N., and Vansuyt G. 1999. Regulation of plant ferritin synthesis: how and why. Cell. Mol. Life Sci. 56:155-166.

Buyer, J. S., Sikora, L. J., and Kratzke, M. G. 1990. Monoclonal antibodies to ferric pseudobactin, the siderophore of plant growth-promoting Pseudomonas putida B10. Appl. Environ. Microbiol. 56:419-424.

Carson, K. C., Meyer, J. M., and Dilworth, M. J. 2000. Hydroxamate siderophores of root nodule bacteria. Soil Biol. Biochem. 32:11-21.

Clough, S. J., and Bent, A. F. 1998. Floral dip: A simplified method for Agrobacterium-mediated transformation of Arabidopsis thaliana. Plant J. 16:735-743.

Curie, C., and Briat, J. F. 2003. Iron transport and signaling in plants. Annu. Rev. Plant Biol. 54:183-206.

Curie, C., Panaviene, Z., Loulergue, C., Dellaporta, S. L., Briat, J. F., and Walker, E. L. 2001. Cloning of ys 1: An iron-regulated maize gene involved in high affinity [Fe III] transport. Nature 409:346-349.

Duijff, B. J., Bakker, P. A. H. M., and Schippers, B. 1994. Ferric pseudobactin 358 as an iron source for carnation. J. Plant Nutr. 17:2069-2078.

Duijff, B. J., Recorbet, G., Bakker, P. A. H. M., Loper, J., and Lemanceau, P. 1999. Microbial antagonism at the root level is involved in the suppression of fusarium wilt by the combination of nonpathogenic Fusarium oxysporum Fo47 and Pseudomonas putida WCS358. Phytopathology 89:1073-1079.

Eide, D., Broderius, M., Fett, J., and Guerinot, M. L. 1996. A novel ironregulated metal transporter from plants identified by functional expression in yeast. Proc. Natl. Acad. Sci. U.S.A. 93:5624-5628.

Elasri, M., Delorme, S., Lemanceau, P., Stewart, G., Laue, B., Glickmann, E., Oger, P. M., and Dessaux, Y. 2001. Acyl-homoserine lactone production is more common amongst plant-associated than soil-borne Pseudomonas spp. Appl. Environ. Microbiol. 67:1198-1209.

Guerinot, M. L., and Yi, Y. 1994. Iron: Nutritious, noxious, and not readily available. Plant Physiol. 104:815-820.

Henriques, R., Jasik, J., Klein, M., Martinoia, E., Feller, U., Schell, J., Pais, M. S., and Koncz, C. 2002. Knock-out of Arabidopsis metal transporter gene IRTI results in iron deficiency accompanied by cell differentiation defects. Plant Mol. Biol. 50:587-597.

Hohnadel, D., and Meyer, J.M. 1988. Specificity of pyoverdine-mediated iron uptake among fluorescent Pseudomonas strains. J. Bacteriol. 170:4865-4873. 
Jaillard, B., Ruiz, L., and Arvieu, J. C. 1996. pH mapping in transparent gel using color indicator videodensitometry. Plant Soil 183:85-95.

Kloepper, J. W., Leong, J., Teintze, M., and Schroth, M. N. 1980. Pseudomonas siderophores: A mechanism explaining disease-suppressive soils. Curr. Microbiol. 4:317-320.

Lemanceau, P., and Alabouvette, C. 1991. Biological control of fusarium diseases by fluorescent Pseudomonas and non-pathogenic Fusarium. Crop Prot. 10:279-286.

Lemanceau, P., Bakker, P. A. H. M., De Kogel, W. J., Alabouvette, C., and Schippers, B. 1992. Effect of pseudobactin 358 production by Pseudomonas putida WCS358 on suppression of fusarium wilt of carnations by nonpathogenic Fusarium oxysporum Fo47. Appl. Environ. Microbiol. 58:2978-2982.

Lemanceau, P., Bakker, P. A. H. M., De Kogel, W. J., Alabouvette, C., and Schippers, B. 1993. Antagonistic effect of nonpathogenic Fusarium oxysporum Fo47 and pseudobactin 358 upon pathogenic Fusarium oxysporum f. sp. dianthi. Appl. Environ. Microbiol. 59:74-82.

Lescure, A. M., Proudhon, D., Pesey, H., Ragland, M., Theil, E. C., and Briat, J. F. 1991. Ferritin gene transcription is regulated by iron in soybean cell culture. Proc. Natl. Acad. Sci. U.S.A. 88:8222-8226.

Lindsay, W. L. 1979. Chemical Equilibria in Soils. J. Wiley and Sons, New York.

Lobréaux, S., and Briat, J. F. 1991. Ferritin accumulation and degradation in different organs of pea (Pisum sativum) during development Biochem. J. 274:601-606.

Loper, J. E., and Buyer, J. S. 1991. Siderophores in microbial interactions on plant surfaces. Mol. Plant-Microbe Interact. 4:5-13.

Loper, J. E., and Henkels, M. A. 1999. Utilization of heterologous sidérophores enhances levels of iron available to Pseudomonas putida in the rhizosphere. Appl. Environ. Microbiol. 65:5357-5363.

Loper, J. E., and Lindow, S. E. 1994. A biological sensor for iron available to bacteria in their habitats on plant surfaces. Appl. Environ. Microbiol. 60:1934-1941.

Masalha, J., Kosegarten, H., Elmaci, O., and Mengel, K. 2000. The central role of microbial activity for iron acquisition in maize and sunflower. Biol. Fertil. Soil 30:433-439.

Meyer, J. M., and Abdallah, M. A. 1978. The fluorescent pigment of Pseudomonas fluorescens: Biosynthesis, purification and physicochemical properties. J. Gen. Microbiol. 107:319-328.

Meyer, J. M., Hallé, F., Hohnadel, D., Lemanceau, P., and Ratefiarivelo, H. 1987. Siderophores of Pseudomonas-biological properties. Pages 188205 in: Iron Transport in Microbes, Plants, and Animals. G. Winkelmann, D. Van der Helm, and J. B. Neilands eds. VCH Verlagsgesellschaft, Weinheim, Germany.

Mirleau, P., Delorme, S., Philippot, L., Meyer, J. M., Mazurier, S., and Lemanceau, P. 2000. Fitness in soil and rhizosphere of Pseudomonas fluorescens $\mathrm{C} 7 \mathrm{R} 12$ compared with a C7R12 mutant affected in pyoverdine synthesis and uptake. FEMS (Fed. Eur. Microbiol. Soc.) Microbiol. Ecol 34:35-44.

Mirleau, P., Philippot, L., Corberand, T., and Lemanceau, P. 2001. Involvement of nitrate reductase and pyoverdine in competitiveness of Pseudo- monas fluorescens strain C7R12 in soil. Appl. Environ. Microbiol. 67:2627-2635.

Moran, R. 1982. Formulae for determination of chlorophyllous pigments extracted with N,N-dimethylformamide. Plant Physiol. 69:1376-1381.

Neilands, J. B. 1981. Iron absorption and transport in microorganisms. Annu. Rev. Nutr. 1:27-46.

Robin, A., Vansuyt, G., Corberand, C., Briat, J. F., and Lemanceau, P. 2006. The soil type affects both the differential accumulation of iron between wild-type and ferritin over-expressor tobacco plants and the sensitivity of their rhizosphere bacterioflora to iron stress. Plant Soil. 75-83.

Robinson, N. J., Procter, C. M., Connoly, E. L., and Guerinot, M. L. 1999. A ferric-chelate reductase for iron uptake from soils. Nature 397:694697.

Stintzi, A., Evans, K., Meyer, J. M., and Poole, K. 1998. Quorum-sensing and siderophores biosynthesis in Pseudomonas aeruginosa: IasR/IasI mutants exhibit reduced pyoverdine biosynthesis. FEMS (Fed. Eur. Microbiol. Soc.) Microbiol. Lett. 166:341-345.

Vansuyt, G., Souche, G., Straczek, A., Briat, J. F., and Jaillard, B. 2003. Flux of protons released by wild-type and ferritin over-expressor tobacco plants: Effect of phosphorus and iron nutrition. Plant Physiol. Biochem. 41:27-33.

Van Wuytswinkel, O., Savino, G., and Briat, J. F. 1995. Purification and characterization of recombinant pea seed ferritins expressed in Es cherichia coli: Influence of amino terminus deletions on protein solubility and in vitro core formation. Biochem. J. 305:253-261.

Van Wuytswinkel, O., Vansuyt, G., Grignon, N., Fourcroy, P., and Briat, J. F. 1999. Iron homeostasis alteration in transgenic tobacco over-expressing ferritin. Plant J. 17:93-97.

Vert, G., Grotz, N., Dedaledechamp, F., Gaymard, F., Guerinot, M. L., Briat, J. F., and Curie, C. 2002. IRT1, an Arabidopsis transporter essential for iron uptake from the soil and for plant growth. Plant Cell 14:111.

Von Wirén, N., Khodr, H., and Hider, R. C. 2000. Hydroxylated phytosiderophore species possess an enhanced chelate stability and affinity for iron (III). Plant Physiol. 124:1149-1157.

Von Wirén N., Mori, S., Marschner, H., and Romheld, V. 1994. Iron inefficiency in maize mutant ys1 (Zea mays L. cv. Yellow-Stripe) is caused by a defect in uptake of iron phytosiderophores. Plant Physiol. 106:7177.

Walter, A., Römheld, V., Marschner, H., and Crowley, D. E. 1994. Iron nutrition of cucumber and maize: Effect of Pseudomonas putida YC 3 and its siderophore. Soil Biol. Biochem. 26:1023-1031.

Yi, Y., and Guerinot, M. L. 1996. Genetic evidence that induction of root Fe (III) chelate reductase activity is necessary for iron uptake under iron deficiency. Plant J. 10:835-844.

\section{AUTHOR-RECOMMENDED INTERNET RESOURCE}

Courtage Analyses Services website: www.onlinecas.com 